In Sund, K. J., Galavan, R. J. \& Huff, A. S. (eds.) 2016.

Uncertainty and Strategic Decision Making,

Series New Horizons in Managerial and Organizational Cognition: Emerald.

ISBN 978-1-78635-170-8

Post-Print version

\title{
A conversation on uncertainty in managerial and organizational cognition
}

\author{
Anne Sigismund Huff \\ Frances J. Milliken \\ Gerard P. Hodgkinson \\ Robert Galavan \\ Kristian J. Sund
}

This book on uncertainty is the beginning of a series titled "New Horizons in Managerial and Organizational Cognition". We asked Frances Milliken and Gerard P. Hodgkinson, two well-known scholars who have made important contributions to our understanding of uncertainty to help introduce the effort. The brief bios found at the end of this volume cannot do justice to the broad range of their contributions, but our conversation gives a flavor of the kind of insights they have brought to managerial and organizational cognition (MOC). The editors thank them for helping launch the series with a decisive exploration of what defining uncertainty involves, how that might be done, why it is important, and how the task is changing. We were interested to discover that all five of us are currently involved in research that considers the nature and impact of uncertainty, and we hope that readers similarly find that paying attention to uncertainty contributes to their current projects. Working together, we can further expand understanding of organizational settings and effective action for both researchers and practitioners.

Keywords: Managerial and organizational cognition, reasoning, behavioural strategy, sensemaking, mental models, risk, neuroscience, decision making, power heuristics, uncertainty

\section{UNCERTAINTY'S CENTRAL ROLE IN STRATEGIC DECISION MAKING}

Huff: Robert, you, Kristian, and I decided as organizers to focus on uncertainty as a dominant theme of the first two Frontiers in Cognition conferences, and as a topic for this book. Can you summarize why you think uncertainty is so important?

Galavan: As you know Anne, I had a career in business before moving to academia. While many of the skills I developed as a manager help me to this day in teaching and research, the transition from working as an engineer to becoming a professor of strategy posed a challenge: getting to grips with the social aspect of organizations and future focused strategy. I can now describe the difficulty as a necessary shift from engineering trained reasoning in absolute and certain terms to learning about making judgments based on relatively uncertain concepts. As I began to study strategy, I was particularly frustrated. Much of the academic literature on strategy, like the literature on engineering, assumes absolute reasoning, which did not fit my empirical observations of strategists or my emerging theoretical explanations. 
It took time to find an academic literature that resonated with me. An important insight, and I am humbled to be in conversation with the author now, came from a wonderful paper by Frances Milliken (1987) that emphasized strategic behavior. Perhaps today, given the popularity of behavioral economics and other multidisciplinary topics, that doesn't seem significant, but back then it was quite radical to put behavior in strategy. The argument at the time was that in the face of uncertainty managers and researchers could either try to be more rational by collecting more data and building better models, or carry on and 'muddle through' - Lindblom's (1959) evocative description of action without strategic guidance.

The concept of behavioral strategy was in turn an important basis for Thomas, Clark and Gioia's (1993) crucial paper on strategic sensemaking. The importance of sensemaking for understanding strategy can't be underestimated. It provides a means for exploring learning and strategizing as non-linear processes rather than value-laden concepts that tend to underpin muddling through. I think we are reaching, perhaps have reached, a point where we can categorize attempts at rational objective strategy making as something that is stronger than muddling through in the face of uncertainty. We understand better the complex learning processes of organizations in the shifting sands of strategic decision making as embracing uncertainty, rather than believing we will somehow overcome uncertainty with rational analysis.

Huff: I agree that strategy research and other management sub-fields have moved to give much greater attention to cognition, uncertainty, and behavioral issues. As those connections have developed, we have become more sophisticated in how we understand uncertainty as an important organizational reality. Frances, you have been an important leader in this effort. Can you say more about your 1987 paper and your current ideas about how uncertainty should be understood?

\section{TYPES OF UNCERTAINTY}

Milliken: In my early work on uncertainty (Milliken, 1987), I was trying to deal with a specific issue that I saw in the field of Organization Theory at the time. The issue was that researchers had created measures of what was then called "perceived environmental uncertainty," which did not correlate very well with so-called objective indicators of environmental volatility, or what was sometimes called "objective uncertainty." One reason why, as we have subsequently come to understand, is that individual managers operating in the same environment can easily perceive that setting in different ways. Another reason why I felt uncertainty needed better definition was that the measures used at the time lumped together what I saw as three very different types of perceived uncertainty. I proposed that when managers are attempting to formulate strategy in response to changes in their organization's environment, they may experience three types of uncertainty:

1) State uncertainty (What will the future environment look like? What are the key trends?),

2) Effect uncertainty (What do these events or trends mean for us in our organization?), and

3) Response uncertainty (What should we do about it?). 
There are a number of interesting implications of distinguishing these types of uncertainty. First, one would expect that only "state uncertainty" would correlate with measures of "objective" volatility. The other types of uncertainty have more to do with the specific relationship between an organization and its environment (what do these events mean for us in particular?). Second, these different types of uncertainty may not necessarily co-vary in expected ways. As I pointed out in the 1987 article, effect uncertainty may actually be at its highest when state uncertainty is at its lowest. Managers, in fact, may be the most motivated to pay attention to their environments when they are pretty sure that there are significant trends occurring (e.g., robotics) but are unsure about how to respond; perhaps because they are uncertain as to what the specific implications of these trends are for their organization. Thus, environmental uncertainty may not be a unitary phenomenon that can be talked about as if the experience of it is always the same. One has to be more specific about the type and source of uncertainty.

Another implication is that there is an implied sequence in the perception of various types of uncertainty. This puts uncertainty into a larger conversation about strategy formulation and sensemaking that emerged in the field in the 1980s and continues to be important (Daft and Weick, 1984; Dutton \& Jackson, 1987; Gioia \& Chittipeddi, 1991; Isabella, 1990; Meyer, 1982; Thomas, Clark \& Gioia, 1993; Weick, 1995; Weick, Sutcliffe, \& Obstfeld, 2004).

My thinking about the role of uncertainty in organizations has broadened considerably since my early work in this area. There are so many things that managers might be uncertain about (whether or not given events or trends will occur, what their impact will be, what the probability associated with various outcomes might be, what the future of a particular technology looks like, who will re-conceive their business and how, what you should do, etc.). No matter what type of uncertainty is perceived, I believe the experience of uncertainty is fundamental to the sensemaking process of managers and humans more generally.

One of the things that I find very interesting is that our business rhetoric places a very high value on confidence and certainty, as Robert has already noted. We pretend to know, or at least be able to estimate, things that we cannot know (the future value of stocks, for example). This causes a common phenomenon in the world of business, which is the denial or obfuscation of uncertainty. Lipshitz and Strauss (1997) use the terms "suppression" or "assumption making" to describe a similar phenomenon. For example, in the business world, people often assign probabilities to the likelihood of future events as if we know what they are with certainty. We then proceed to use models with these probability estimates as if they conveyed the truth when they actually make assumptions about things that are fundamentally uncertain. The problem is that economists, other academics, analysts, and managers tend to forget that the estimator actually did not know the probability. Tacit assumptions of confidence, can lead to believing that we know things that we do not know and to thinking that we are making decisions under conditions of risk rather than decisions under conditions of uncertainty, which, in turn, can lead to poor quality and dangerous decisions.

One of the reasons why we want to pretend that we are confident in our beliefs is that admitting uncertainty is tough. Uncertainty is associated with lack of control, which creates stress and anxiety. Dawes (1988) asserts that we dread uncertainty, which is one of the reasons that we often deal with it by ignoring it. Consider, climate change as a case in point. Admitting 
uncertainty is especially tough for managers who are supposed to know what is going on and who live in the world where the rhetoric of business is to pretend to know things that one cannot possibly know with certainty. Academics also have to recognize we too are invested in appearing to "know" things. If we recognized uncertainty more often in our classrooms, we might offer managers and other organizational participants more realistic models of perception, interpretation, decision making, and strategic planning. However, realistically, we will also create anxiety for our students and for ourselves.

Huff: That is a great introduction to why uncertainty is such an important but slippery topic for managers and researchers, Frances. One of my first publications attempted to add another point. It was titled "Consensual Uncertainty" (Huff, 1978) and argued that disagreement about uncertainty among interacting stakeholders creates an especially problematic kind of doubt. Divergence in perceptions of uncertainty can have many causes, including different experiences and trajectories (Barr, Stimpert and Huff, 1992). This suggests an additional complexity: perceptions of uncertainty are likely to shift over time, in part due to learning, a process which is uneven and particularistic. In short, purposeful action is made much more difficult when participants do not even agree about whether there is uncertainty, or its nature. So I would add to your list:

4. Uncertainty due to difficulties in understanding differences in interpretations among observers, and

5. Uncertainty from unpredictable changes in perceived uncertainty due to learning and shifting attention at all levels of analysis.

Kristian, you drew on Frances' work in a paper you published in 2015. What do you feel are the outstanding issues in this area?

Sund: I was drawn to the uncertainty construct whilst working on my doctoral dissertation. As a trained economist I had grown up in a world similar to what the three of you describe: risk is acknowledged and decisions are made under conditions of asymmetries of information, but relatively little attention is given to the concept of uncertainty. The underlying assumption in the literature I read was that, if necessary, more information could be obtained to yield the 'right' decision.

During my studies I had the opportunity to sit in on strategy meetings in a number of companies, and what I saw reminded me firstly of Herbert Simon's (1979) description of satisficing behavior, rather than profit maximizing behavior, and secondly it exhibited the kind of muddling that Robert refers to. Managers appeared to me to be very unclear about changes in the environment, about competitors' actions, about customers, and they seemed to deal with this uncertainty by setting very general targets, ones they hoped would be incremental improvements to the status quo, yet satisfy owners. These observations made me interested in the cognitive aspects of strategy.

Now, as then, most organization theory textbooks cite Duncan's (1972) work on environmental uncertainty, often noting how uncertainty acts as a data contingency factor when designing organizations. However, since his work in the early 70s, we have learned how perceptions of 
uncertainty, in addition to and I believe more importantly than, objectively measured uncertainty affects decision making. Frances' $(1987,1990)$ work indeed helps researchers conceptualize issue-specific subjective uncertainty and be more accurate in what we mean by uncertainty.

What I have observed in my empirical work is that CEOs in the same industry, facing the same task environment, perceive industry trends very differently, and declare different levels of uncertainty (Sund, 2013). We know relatively little about what drives such differences. Access to information and prior experience may only be part of the story. For example, we know little about the details of links that could exist between individual personality traits and different types of perceived uncertainty. Work on overconfidence could be a step in this direction, something I discuss in my own chapter in this volume (Sund, 2016). Some managers may systematically feel lower state uncertainty than their peers, and be overconfident in their own probability estimates. I think there are also some links here to your work on bias, Gerard.

Hodgkinson: There are indeed some very interesting interconnections with my work, but these extend way beyond my work on cognitive bias per se. My fascination with cognition in the strategic management process began thirty years ago, when in late 1986 I took up a research post at Manchester Business School. I was employed to work on a project investigating managers' mental models of competitive industry structures and discovered that, contrary to the neoclassical economic orthodoxy that permeated the leading strategy textbooks and journals of the time, organizational decision makers within and between organizations in the UK grocery retail sector held radically different perceptions of "the business environment," even though they faced similar material circumstances and strategic contingencies (Hodgkinson \& Johnson, 1994). Our findings ran contrary to the body of work that was then emerging, which suggested that strategists within a given sector would be expected to hold highly similar representations of strategic knowledge (cf. Porac, Thomas, \& Baden-Fuller, 1989).

As a young psychologist, inculcated into and (at that time) bound by the strictures of positivism, I struggled both intellectually and emotionally to come to terms with our empirical findings, a problem that was exacerbated by the fact that my immediate colleagues did not uniformly share my objectivist world view, being from a range of disciplinary backgrounds. Subsequently, in my doctoral thesis I explored this puzzle at length, attempting to disentangle competing theoretical and methodological perspectives within the (then) extant literature and develop a more unified account of the socio-cognitive dynamics pertaining to rivalry, by constructing a multilevel longitudinal dataset.

I elaborate my early experience to this level of detail to illustrate that, in embarking on cognition research, my frustrations were similar to but also different from those experienced by Kristian. On the one hand, the cognitive perspective I was comfortable with was firmly rooted in the objectivist certainty of the computational tradition of Newell and Simon (1976), and Tversky and Kahneman (1981), which is ontologically similar to Kristian's starting point. But the majority of the research team to which I belonged were much closer to the interpretivist tradition of Weick $(1969,1979,1995)$ with which Kristian and Anne were (and are) clearly comfortable, but I was just beginning to appreciate in my early career. These distinctly different viewpoints lie at the heart of the literature on risk and uncertainty. Over the course of my subsequent doctoral 
research (Hodgkinson, 1993), I came to realize that there are grains of truth in each (see Hodgkinson, 2005, 2015).

After I demonstrated the veracity of competitive enactment and related Weickian notions as an explanation of both industry blind spots and collective inertia in the first decade of my research career, I turned my attention to theorizing and experimenting with tools and techniques that might help improve the practice of strategizing. It is at this juncture that my interest in Kahneman and Tversky's work on heuristics and biases was (re)awakened. I wondered whether some of the knowledge elicitation/cognitive mapping tools that were used to demonstrate the potency of cognitive phenomena (e.g. Huff, 1990) might also be used as a foundation for intervening in strategy making processes and attenuating recognized problems. Soon after completing my doctoral studies I moved to a senior lectureship at the University of Leeds. With a group of colleagues who had an interest in behavioral decision making, I was lucky enough to win a competitive award from the UK Economic and Social Research Council under its 'Risk and Human Behaviour Programme'.

Thus began a program of work directed toward the development and validation of causal cognitive mapping techniques as a basis for enriching strategic thought and attenuating cognitive biases of the sort identified by Kahneman and Tversky and well-understood in the strategy literature. By way of illustration, my colleagues and I demonstrated the efficacy of these techniques for attenuating the framing bias through a combination of laboratory and experimental field studies (Hodgkinson et al., 1999; Hodgkinson \& Maule, 2002).

Framing bias arises when trivial changes to the way in which a decision problem is framed in terms of potential gains or potential losses, lead to reversals of preference. Decision makers had been shown to be typically risk averse when gains were highlighted and risk seeking when losses were highlighted (Kahneman \& Tversky, 1984). The remedy for avoiding the potential pitfalls of this bias is to adopt procedures "that will transform equivalent versions of any problem into the same canonical representation" (Kahneman \& Tversky, 1984, p. 344) in order to bring about the normatively desirable state of affairs in which individuals' preferences conform to the basic axioms of rational choice. In other words, decision makers need to elaborate their models of the problem at hand in ways that take into account both the potential gains and potential losses at stake, thus ensuring that trivial features of the decision context do not influence choice behavior unduly.

Underpinned by dual-process theories of reasoning, judgment, and social cognition, our approach generally sought to develop and validate tools that would force their users to 'switch cognitive gears' (Louis \&Sutton, 1991). Kahneman (2011) summarizes the considerable literature on automatic processes which if left unchecked risk biased outcomes of varying types. My own book with Paul Sparrow (Hodgkinson \& Sparrow, 2002) includes an effort to do the same thing.

More recently I have been influenced by advances in the social neurosciences (e.g. Lieberman, 2007; Loewenstein, Rick, \& Cohen, 2008), which suggest that such 'cold' conceptions of risk and uncertainty are problematic, not least because the stimuli that trigger all three of the types of perceived uncertainty identified by Frances Milliken (1987) are rarely, if ever, processed in an affectively neutral manner. On the contrary, as demonstrated by some of my latest research, the 
issues that warrant the label 'strategic' trigger wide variations in emotional valuation by organizational decision makers (Hodgkinson \& Healey, 2011, 2014; Hodgkinson, Wright, \& Anderson, 2015).

\section{UNCERTAINTY WITHIN TEAMS AND ACROSS LARGER COLLECTIVES}

Huff: We've just summarized an important set of ideas about the nature of uncertainty, but I think there is even more to be said. For example, you have focused on uncertainty in teams, Frances. What has that work produced for our understanding of uncertainty?

Milliken: Anne, as you noted earlier, one key question is whether or not there is consensus in how certain or uncertain the environment is perceived to be. This relates to a larger conversation about whether there is agreement about perceptions and interpretations of events in general whether in a team, in an organization, or any other collective. It is a central issue in the study of group decision making. Groups, teams, and larger collectives can either use disagreement to fuel information seeking and sharing, or they can engage in efforts to suppress disagreement by exerting pressure on the dissenters to agree. This introduces the topics of politics and conflict resolution into the mix.

To complicate the matter even further, not everyone has an equal opportunity to offer their opinion in the hierarchies that dominate cognitive processing and collective action. Even if someone has the opportunity, they may not feel comfortable taking on a dissenting role. So there can be a false assumption of consensus that the environment is well understood, but that consensus is produced by the choice of governance structures and processes. This is another way in which uncertainty about the environment can be obscured and it points toward one of my current interests - the obstacles to optimal information flow and their consequences in teams and organizations.

Hodgkinson: I will add a further complication. Work that I am undertaking with my colleagues Mark Healey and Timo Vuori, has begun to consider how the effects of less conscious and deliberative forms of cognition might undermine the attempts of teams to coordinate their efforts. Specifically, we have been reflecting on the implications of dual-process formulations for (re)theorizing team cognition and team coordination (Healey, Vuori, \& Hodgkinson, 2015).

The problem is that by focusing on mental models that are conscious and deliberative, team research has assumed that cognitive sharedness is unimodal: that is, it operates at a single level of deliberative cognition. Informed by advances in social neuroscience, in recent years dualprocess theorists (e.g. Lieberman, 2007) instead have advanced 'parallel competitive' accounts of reasoning, judgment, and social cognition that are of a different kind than the 'defaultinterventionist' conceptions underpinning earlier cognitive work in the strategy literature (e.g. Dutton, 1993; Hodgkinson \& Maule, 2002; Reger \& Palmer, 1996).

Default-interventionist theories assume that automatic and controlled information processing systems operate in sequence, with the controlled system shutting off the automatic system when 
(scarce) cognitive capacity is needed and available. Within classic models, the default mode of information processing is through the operation of System 1 processes, the prime objective being to conserve scarce, System 2 resources, using the latter to intervene only when necessary. Parallel competitive models, in contrast, assume that the controlled and automatic systems operate simultaneously. And this is important: the automatic system continues to function even when the controlled system is active. Parallel competitive models are based on two key assumptions: (a) the two systems contain distinct cognitive and affective content, and (b) they exert competing influences on behavior.

These ideas have immense implications for understanding why and how teams that are seemingly in close agreement with respect to their perceptions of the environment nevertheless fail to coordinate their actions with respect of the risks and uncertainties confronting them. In hindsight, the reason for this paradox is obvious. In confining their attention to deliberative, conscious cognition, researchers studying teams have neglected important less mindful cognition, including implicit attitudes (Greenwald \& Banaji, 1995), subconscious goals (Latham, Stajkovic, \& Locke, 2010), and implicit stereotypes (Banaji, Hardin, \& Rothman, 1993).

Despite growing appreciation in organizational research of automatic system processes at the individual level, teams research has not kept pace with these developments. Instead, researchers tend to assume that shared, deliberative mental models both of the task environment and the team's capabilities are likely to exist, and that these models are the key determinants of team coordination and effectiveness. Our work suggests that although these two types of 'reflective' cognitive content are important, sharing deliberative mental models of the task and team is often insufficient for effective team performance. To function effectively, teams must also share task and team cognition at the 'reflexive' level. In other words, even when teams share highly similar explicit mental models of the uncertainties and risks confronting them and are in basic agreement regarding how those uncertainties and risks might be addressed (reflective consensus), divergent subconscious goals and implicit attitudes and stereotypes antithetical to harmonious, coordinated action (a lack of reflexive consensus) can undermine the team's efforts. Conversely, teams with low levels of reflective consensus are sometimes able to function effectively because they are united by a shared reflexive sense of purpose (i.e. shared subconscious goals) and concomitant routines that coordinate their efforts.

Our work has thus begun to develop a more complete understanding of shared cognition and its influence on team processes and outcomes. By incorporating the insights of parallel competitive accounts of reasoning, judgment, and social cognition, this work is extending team cognition theory to include automatic processes that are more visceral and affective in nature. As I mentioned earlier, such 'hot' cognition is integral to how decision makers address risks and uncertainties. It is a fundamental determinant of how human beings interact with one another. And of course it affects key organizational activities, like planning.

\section{PLANNING WHILE RECOGNIZING UNCERTAINTY}

Sund: I believe what Gerard is pointing to here is important. For a number of years I have been working with various actors in the postal sector, which has been facing tremendous uncertainties. 
Some of my recent work has been on their efforts at business model innovation. It turns out one of their challenges is that top management on one hand claim to understand the need for innovative changes to their business to move away from the declining letter market, but on the other hand clash with middle managers in their most innovative business units, and in the end make decisions firmly rooted in the logics of the old core business (Sund, Villarroel, \& Bogers, 2014). This could well be indicative of a lack of the kind of reflexive consensus Gerard talks about.

A statistic I recently came across has renewed my interest in strategic decision making under conditions of perceived uncertainty. Bain \& Company report in their Management Tools \& Trends (Rigby and Bilodeau, 2015), that since the start of the financial crisis in 2007, the percentage of companies declaring that they use strategic planning as a management tool has dropped from over $80 \%$ to a little over $40 \%$. In other words, over half the companies they survey yearly have dropped strategic planning (or at least say they have done so). I interpret this as a reaction to the uncertainty of the financial crisis and subsequent economic recession that has led management to think more short term, and it probably works at both the conscious and nonconscious levels of processing that you just described, Gerard. It is tempting to bury strategic planning as uncertainty increases, as Frances reminds us, but instead I think there is a challenge for management educators to help managers reengage with longer-term thinking, despite uncertainty.

Hodgkinson: George Loewenstein and colleagues (Loewenstein, 2006; Loewenstein, Rick, \& Cohen, 2008) demonstrate that one of the reasons decision makers avoid uncertainty is because they are unable to deal effectively with the negative emotions it often engenders. Their research on what they call "the pleasures and pains of information" in economic decisions draws directly on neuroimaging studies showing that information signaling negative prospects activates regions of the brain's pain matrix.

Because people derive pain not only from lost material benefits, but also directly from information processing, they avoid painful information even when it also suggests long-term benefit. Instead, decision makers satiate on pleasurable information, even if it provides only marginally functional gains. For example, based on this foundation, Karlsson, Loewenstein and Seppi (2009) analyzed computerized records to show that investors typically manifest an 'ostrich effect' by scrutinizing their stocks more intensively when the general stock market is up, relative to when it is down, thus reducing if not avoiding altogether the pain of negative information. My own experience in the world of practice, as a facilitator of scenario planning workshops designed with the aim of helping decision makers to deal with the uncertainties confronting their organizations attests to the veracity of the ostrich effect (see Hodgkinson \& Wright, 2002).

Huff: That's a compelling metaphor. Robert, one reason why your work on EU security is of interest to me is that the ostrich effect is apparent but increasingly difficult to maintain. You are working in situations that are obviously uncertain and differentially experienced. Yet the need for more coordinated action is incredibly strong and it appears from the outside that some progress is being made. 
Galavan: I am involved with the Edward M. Kennedy Institute for Conflict Intervention, and the work we have been doing in this area has given us interesting insights into how different organization types deal with uncertainty. Uncertainty in the contexts we study is quite extreme, usually involving a failed or fragile nation-states and is therefore high on all three uncertainty dimensions that Frances identifies as well as the pain index Gerard points us toward. There is quite a range of actors involved, which as we already noted is likely to generate different perceptions of uncertainty and different activity patterns. I will focus here on two groups of actors for the contrast they provide: leaders of military operations and diplomats.

What we find, and I vastly oversimplify here, is a military that works together with a common language, has a common culture, and expends significant planning time to understand objectively their capabilities. Their approach to strategy making is to focus on an end state, with a common terminology describing the use of ends, ways, and means, which could also be framed as objectives, concepts, and resources (Lykke, 1997). Uncertainty is managed by military actors when they tightly define very general objectives (eliminating complexity) and then use wellrehearsed processes to develop that concept and accurately specify its resource requirements.

In stark contrast, diplomats have no potential to narrow an objective or eliminate its complexity. In their arena there is no end, only an ongoing and often intensive process of negotiation. For example, the Political and Security Committee of the European Union meets for two full days each week; more often if deemed necessary. This takes far more time than any strategy committee would invest in a commercial organization. The diplomats we observe are in a constant state of monitoring, and potentially an almost constant state of negotiating. They work with many actors, especially political leaders, and must also try to communicate the results of their efforts to the general public. Their means of handling uncertainty is to maintain a highly vigilant state of awareness and flux, moving forward in small steps, sensing reactions, and responding accordingly. They can never be quite sure what the objective is (at least in any meaningful timeframe). They deal with shifting and contested concepts. They can influence but have little direct control over resources.

Both groups have evolved ways of working to suit their historical demands. The military have the capabilities to take decisive, controlled, and well specified actions. They are less suited to running societies, although clearly some have not read that memo. At the same time, politically astute diplomats are well suited to dealing with multiple competing agendas, value sets, and fuzzy objectives. They are less suited to rapid and coherent rallying of resources. What these actors and the others involved (e.g. NGOs, civil servants) have to embrace is a recognition that effective solutions must rely on a "both and" logic, not on "either or". More specifically, the European Union is developing a concept known as the "comprehensive approach". It seeks to recognize that complex contexts need complex and comprehensive responses. As we know, adopting this stance has been a difficult challenge for all involved.

I see lots of parallels here with developments in other kinds of organizations, particularly knowledge-based service organizations. In almost all organizations the classic, but now largely abandoned, military model of command and control from which early organizations developed their approach, is rapidly breaking down. Knowledge is not generated on the basis of command and certainly not from the top down. Borders are permeable and solutions are often co-created 
with customers, suppliers, and competitors. Arguably, the need to understand uncertainty, especially within and across companies and networks, is getting much more difficult and even more important than it was in the early period of developing key concepts in managerial and organizational cognition.

\section{AN AGENDA FOR FUTURE WORK ON UNCERTAINTY}

Milliken: There are three topics I think will be particularly important as we move forward with the study of strategic decision making in general and perceived uncertainty more specifically. Each of the three topic areas reflect my own interest in the fundamental processes by which individuals make sense of their worlds and then act as a result of their interpretations. The other participants in this conversation are primarily interested in strategic management research. I offer these topic areas as ones that have relevance to strategy, but are equally relevant to those who work in organization behavior, HR, and organization theory, among other domains.

1. Study the consequences of the changing nature of organizations. To quote from Barley and Kunda (2006:55): "The collapse of bureaucracy and the blurring of the boundaries of firms is the most widely acknowledged change associated with the shift to a post-industrial economy". We, as researchers, need to consider whether (and how) our thinking about MOC needs to change as a consequence. We must acknowledge and try to understand the implications of the shift to a post-industrial world and its impact on how we should now think about uncertainty, cognition, sensemaking, sense-giving, and strategic decision making. One obvious area of importance is to study information flows in networks, especially networks that span organizational boundaries.

2. Pay attention to power and information flows in and around organizations. Organizations are hierarchies and not everyone has an equal say in organizational sensemaking efforts because of differences in power. Earlier in this conversation I said that I am very interested in the current research on information flows in organizations. It seems to me that we have tended to assume that information flows smoothly around organizations and up hierarchies but this assumption is far from the truth - despite the great increase we now have in sources, uses, and communication of information. My particular interest at the present time is in what I might call "distortions" in upward communication flows. That is, what do employees not say to their bosses and how do these decisions affect what managers know (and do not know) about how their organization operates. This is related to the earlier discussion of the difficulty people have in discussing painful topics; especially potentially threatening ones.

I would point to two arenas that especially need further research:

The problem of upward communication in organizations and its implications for decision making and organizational learning. To tie this in with my thinking on uncertainty, my hunch is that managers may be more confident (certain) that they know what is going on than they should be. This is because there are enormous incentives in place for lower-level employees to tell managers what they want to hear and to leave out information that signals that 
there is uncertainty about the effectiveness of a strategy or conveys other negative feedback (Fang, Kim, \& Milliken, 2014; Milliken \& Lam, 2009). Employees often have little incentive to convey negative feedback or bad news to managers.

Study the effects of power on sensemaking and sense-giving. Weick, Sutcliffe and Obstfeld (2005) discuss the need for more exploration of power and sensemaking. While my research on upward communication is about the failure of upward communication, other people have focused on how people in power attempt to "give sense" to others (Gioia and Chittipeddi, 1991). Powerful people, for example, may try to persuade less powerful people that they, the leaders, understand conditions in the organizational environment, thereby "helping" the less powerful to deal with the anxiety created by their own uncertainty. But, of course, this is motivated sense-giving. While such "sense-giving" efforts may seem necessary to create action, it is also possible that "sensegiving efforts have the unintended consequence of blocking the upward flow of any information that is inconsistent with the view of the world propagated by the managers. This in turn can block strategic change initiatives at the very time that they are most needed. It is an interesting puzzle for researchers and managers to navigate.

3. Emphasize teams as a locus of decision making. Organizations rely on teams to manage projects and make decisions but we need to know more about how to improve teams' performance on decision-making tasks. I think there is still much more work to be done in the area of decision heuristics and how they affect decision-making processes in organizations. In particular, we need to think about what factors influence whether decisionmaking teams are more or less likely to be susceptible to the use of decision heuristics than individuals. As I mentioned earlier, another key area, in my opinion, is to improve our understanding of how groups deal with disagreement. Our objective should be to give better advice to managers about how to manage disagreements in a way that captures cognitive richness.

Sund: I have often heard others say that cognition research somehow "bridges" the traditional functional domains of research (strategy, HR, organization theory, and so on), as Frances suggests, and I agree. What is missing for me are some theoretically defined and empirically measured links between specific major theories and their cognitive microfoundations. What I mean by this can be expressed with the following specific examples:

4. Explore multi-level links between cognitive and management theories. There are a number of very important (organizational-level) theories that have gained prominence since the 1990s across multiple fields (not just in strategy) and that clearly have some links to cognition. Firstly, I would mention the knowledge-based view of the firm (Grant, 1996; Nonaka, 1994). Knowledge, its creation and transfer between actors is, in this view, at the very heart of organizational endeavours, yet we know relatively little about the link between this knowledge content and our theories of knowledge structure. For example, how do cognitive biases at the individual level affect subsequent knowledge value creation at the organizational level? Another example is the idea of absorptive capacity, defined as the 
"ability of a firm to recognize the value of new, external information, assimilate it, and apply it to commercial ends" (Cohen \& Levinthal, 1990, p. 128). The concept is incredibly similar to Daft and Weick's (1984) notion of the interpretative process of collective sensemaking, yet what Pandza and Thorpe (2009) have labelled the "managerial agency in creating and shaping dynamic capabilities" has rarely been explored. This call for more work on the cognitive microfoundations of grand theories of strategy (Foss \& Lindenberg, 2013), can be seen as an opportunity to seek some form of unifying structure between macro- and microlevel theories, and is actually at the heart of much of the work that has taken place in MOC.

Hodgkinson: As I hope I have conveyed in my earlier remarks, I sense that MOC is at an exciting stage in its development. Concepts and theories that have been foundational to our scholarly community's work from the field's inception are reaching the end of their shelf life in my opinion. New work that addresses this fundamental problem needs to gather momentum and to this end I would like to highlight two pressing priorities:

5. Focus on adaptive rationality. Conventional bounded rationality conceptions of decision makers as (ineffective) cognitive misers are receiving increasing criticism from scholars, from a wide range of perspectives (cf. Gigerenzer \& Gaissmaier, 2011; Hodgkinson \& Healey, 2008, 2011; Lant \& Shapira, 2001; Lipshitz, Klein, Orasanu, \& Salas, 2001; Sutcliffe $\&$ Weick, 2008). In the wake of these developments, organization theory and strategy scholars are advancing alternative conceptions of heuristic and intuitive decision processes ones that are adaptively rational (cf. Bingham \& Eisenhardt, 2011, 2014; Hodgkinson, Langan-Fox, \& Sadler-Smith, 2008; Hodgkinson, Sadler-Smith, Burke, Claxton, \& Sparrow, 2009; Salas, Rosen, \& DiazGranados, 2010; Vuori \& Vuori, 2014). This work is providing a much-needed counterweight to the classical view that has emphasized the 'down-sides' of heuristics and intuition as means of addressing uncertainty in an unpredictable world. However, we need to understand better the generative mechanisms underpinning the genesis and evolution of adaptively rational heuristics and the boundary conditions that limit their effectiveness. Relatedly, we need a programme of work to extend recent nascent attempts to integrate the insights of the classic heuristics and biases programme of work with more naturalistic conceptions of intuition (Kahneman \& Klein, 2009, 2010).

6. Pay special attention to 'hot' cognition. Drawing on recent advances in social neuroscience, some of which I have alluded to above, strategy and organization theory researchers have begun to eschew 'cold' conceptions of cognition in favour of 'hot cognition' alternatives (e.g., Healey \& Hodgkinson, 2014; Hodgkinson \& Healey, 2011, 2014; Huy, 2011, 2012; Liu \& Maitlis, 2014; Powell, 2011; Powell \& Puccinelli, 2012). For instance, Hodgkinson and Healey (2011) revisited the core psychological assumptions underpinning Teece's (2007) influential dynamic capabilities framework, with the aim of developing a more complete picture of the psychological challenges associated with developing dynamic capabilities. We demonstrated that the biases and inertial forces that undermine strategic adaptation have emotional roots as well as cognitive ones. Our analysis highlights "the need for a new generation of knowledge elicitation and decision-aiding techniques, predicated on hot cognition principles, for both intervention and research purposes" (p. 1512). 
Responding directly to this challenge, I recently led a small-scale two-study project that demonstrated the feasibility of adapting the repertory grid technique, an approach to cognitive mapping that is well-established in strategic management (Huff, 1990; Huff \& Reger, 1987; Walsh, 1995; Wright, 2004, 2008), as a basis for amassing the empirical evidence required to test and extend theory and research predicated on hot cognition principles (Hodgkinson, Wright, \& Anderson, 2015). Departing from the "cold cognition logic" currently prevailing, we proposed metacognition, emotion management, and self-regulation as core dynamic managerial capabilities.

The resulting method and others like it have the potential to benefit strategic decision makers and strategy workshop facilitators in their efforts to intervene in decision making processes. By forcing decision makers to reflect emotionally on the issues at hand, a process known as emotional reframing (Powell, 2011), the adoption of such techniques should equip organizational decision makers with the ability to sense with greater alacrity the need for mental model change and then shift their strategic choices accordingly. Clearly an important next step is to utilize our new method in larger scale longitudinal studies that track how the interplay of hot and cold cognition co-evolves overtime and in what direction(s) and with what magnitude(s), drawing out the potential implications for reframing as an aid to strategic adaptation in the face of uncertainty.

Galavan: Well it is a fantastic list already, so rather than nuance some of the points made I want to point to two aspects that have not been mentioned at all, but are important complements. First, we should remember that uncertainty is not randomness. Even chaotic systems have embedded patterns and those patterns, while not always obvious at first glance, generate an underlying fabric into which the complex story is woven. One of the potential pattern generators that I have been exploring with Liam Lacey is values (Lacey \& Galavan, 2015). Values have been lost to a large extent under a wave of work on agency theory (Jensen \& Meckling, 1976) and the assumptions it brings about self-serving agents in need of external incentives to shape their behaviour. I commend reasserting it in MOC.

7. Recognize the centrality of values in decision making and the organisational means by which they are crowed out. Gerard mentioned the importance of "subconscious goals and implicit attitudes" and values must play a role in our understanding of these drivers. At the risk of normative prescription, it strikes me that values are an important stabilizing mechanism in the face of uncertainty and I am confident practitioners recognize this, even if it is not foremost in out literature. In one of the extreme contexts that we studied a senior manager was explicit about the role of values in a risk laden post-conflict environment, explaining the need to both develop a set of values and then to 'patrol those values' (Galavan, Murphy and Braniff, forthcoming). I believe we do a service to management as a profession by examining the mechanisms through which individual and social values develop and operate in organizations.

The second call I have is for research that further embraces a wider definition of cognition. We have an ethical responsibility to ensure that our research improves the lives of our subjects managers and other decision makers grappling with the challenges of uncertainty. Our research must therefore address their needs as people, not merely hosts of cognitive structures. 
8. Examine uncertainty from a holistic perspective. Cognition research is not brain research and I have concerns in relation to its rather crude, but nevertheless alluring draw to deconstruction. The most demanding draw is currently neuroscience. While without a doubt, understanding the brain adds to our understanding of cognition, it removes cognition from its sentient human host. I would like to see some of our work broaden out and embrace philosophical premises and ethical considerations in a more holistic way.

Huff: It is not easy to add to this impressive list, but I will follow Robert's lead by suggesting a few more expansions.

9. Pay attention to the increasing importance of social media in creating and shaping perceived uncertainty. There is a strong but unpredictable 'contagion' of sensemaking among individuals through social media that can derail plans in unexpected ways (Huff, 2016). As organizations become more open to involvement with 'outsiders,' by choice and by necessity, they face more unpredictable, and largely uncontrollable, interactions. So far, money and marketing expertise seems to have relatively little effect on social media conversations.

On a related theme, we have not addressed the changing nature of uncertainty due to the move from analogue to digital information processing. A particularly interesting and important area of new research has to do with the number of 'decisions' made without human attention. Thus another compelling area for new research is to

\section{Reconsider uncertainty in a world dominated by sensors and tracking, the increasing} collection of big data sets, and algorithmic decision rules. The average person is on film hundreds of times a day. Face recognition is increasingly, but not completely, successful in connecting names to these pictures. Data collection of other kinds, especially the records people generate as they use their mobile phones, computers, and other electronic devices (like credit cards and ATMs) creates saleable information at an aggregate level and is increasingly 'curating' the access to information we have at a personal level based on our past behaviour. At the same time, sensing technology now makes it possible and increasingly affordable to gather information from the 'internet of things' that surrounds us. I think we must abandon past desires and expectations for certainty just as we to abandon past expectations and desires for privacy.

Finally, it is somewhat surprising that we have not said much about innovation or entrepreneurship. Important work in this area provides evidence about how decisions are made not only when uncertainty exists about the nature of the world, but also when decision makers are uncertain about their own goals and means.

11. Study actions taking place despite uncertainty. Research on innovation and entrepreneurship considers how managers and other actors (customers, investors, etc.) proceed when they cannot access desirable information. Work on open innovation, for example, looks at what decision makers do when they recognize they must go beyond their own organization and networks to resolve uncertainty. Of particular interest to the current discussion, the search 
can end by reconceptualising the frame within which uncertainty was first defined (Huff, Huff \& Reichwald, 2013). Considering an even deeper uncertainty, work on effectuation by Saras Saravathy and her colleagues (see effectuation.org) considers how experienced entrepreneurs generate ideas even though they are unclear about what they are developing or how they will create it. Those interested in design, in contrast, focus on creating new meanings rather than interact with extant meaning (e.g. Verganti, 2013). In short, I recommend that some researchers interested in uncertainty look at changing definitions of how opportunities to act are defined (Venkataraman, et al., 2012).

\section{CONCLUSION}

As a concluding note from all five of the participants in this conversation, we will merely say that we hope readers are as energized as we are about finding new research opportunities to address critical organizational issues.

\section{REFERENCES}

Banaji, M. R., Hardin, C., \& Rothman, A. J. (1993). Implicit stereotyping in person judgment. Journal of Personality and Social Psychology, 65(2): 272-281.

Barley, S. \& Kunda, G. (2006). Contracting: A new form of professional practice. Academy of Management Perspectives, 20: 45-66.

Barr, P. S., Stimpert, J. L., \& Huff, A. S. (1992). Cognitive change, strategic action, and organizational renewal. Strategic management journal, 13(S1): 15-36.

Bingham C., \& Eisenhardt K. 2011. Rational heuristics: the "simple rules" strategists learn from their process experiences. Strategic Management Journal ,32(13): 1437-1464.

Bingham C., \& Eisenhardt K. (2014). Response to Vuori and Vuori's commentary on "Heuristics in the strategy context". Strategic Management Journal ,35: 1698-1702.

Cohen, W. M., \& Levinthal, D. A. (1990). Absorptive capacity: A New Perspective on Learning and Innovation. Administrative Science Quarterly, 128-152.

Daft, R. \& Weick, K. (1984). Organizations as interpretation systems. Academy of Management Review, 9:284-295.

Dawes, R. N. (1988). Rational choice in an Uncertain World. New York: Harcourt. 
Duncan, R. B. (1972). Characteristics of organizational environments and perceived environmental uncertainty. Administrative science quarterly, 17: 313-327.

Dutton JE. (1993). Interpretations on automatic: a different view of strategic issue diagnosis. Journal of Management Studies, 30(3): 339-357.

Dutton, J. \& Jackson, S. (1987). Categorizing strategic issues: Links to organizational action. Academy of Management Review, 12:76-90.

Fang, C., Kim, J., \& Milliken, F. J. (2014). When Bad News Is Sugar-coated: Information Distortion, Organizational Search and the Behavioral Theory of the Firm. Strategic Management Journal., 35(8), 1186-1201.

Foss, N. J., \& Lindenberg, S. (2013). Microfoundations for strategy: A goal-framing perspective on the drivers of value creation. The Academy of Management Perspectives, 27(2), 85102.

Galavan, R. J., Murphy, J., Braniff, M. (forthcoming) Public Management, Peace-building and Leading change: Public Sector Responses to Transition in Northern Ireland. In Lehner, S. and McGrattan, C. (eds) The Promise of Peace: Revisiting the Northern Ireland Model. Manchester University Press

Gigerenzer, G., \& Gaissmaier, W. (2011). Heuristic decision making. Annual Review of Psychology, 62: 451-482.

Gioia, D., \& Chittipeddi, K. (1991). Sensemaking and sense-giving in strategic change initiatives. Strategic Management Journal, 12: 433-448.

Grant, R. M. (1996). Toward a Knowledge-Based Theory of the Firm. Strategic Management Journal, 17(S2), 109-122.

Greenwald, A. G., \& Banaji, M. R. (1995). Implicit social cognition: Attitudes, self-esteem and stereotypes. Psychological Review, 102(1): 4-27.

Healey, M.P., \& Hodgkinson, G.P. (2014). Rethinking the philosophical and theoretical foundations of organizational neuroscience: A critical realist alternative. Human Relations, 67: 765-792.

Healey, M. P., Vuori, T., \& Hodgkinson, G. P. (2015). When teams agree while disagreeing: Reflexion and reflection in shared cognition. Academy of Management Review, 40: 399422.

Hodgkinson, G. P. (1993). Strategic Cognition in a Mature Industry: Differentiation, Consensus and Outcomes. Unpublished PhD Thesis, University of Sheffield, UK. 
Hodgkinson, G. P. (2005). Images of competitive space: A study of managerial and organizational strategic cognition. Basingstoke, UK: Palgrave Macmillan.

Hodgkinson, G. P. (2015). Reflections on the interplay between cognition, action and outcomes in industries and business markets: What have we learned so far and where might we go next? Industrial Marketing Management, 48: 12-25.

Hodgkinson, G. P., Bown, N., Maule, A. J., Glaister, K. W., \& Pearman, A. D. (1999). Breaking the frame: An analysis of strategic cognition and decision making under uncertainty. Strategic Management Journal, 20: 977-985.

Hodgkinson GP and Healey MP. (2008).Cognition in Organizations. Annual Review of Psychology 59: 387-417.

Hodgkinson GP and Healey MP. (2011). Psychological foundations of dynamic capabilities: Reflexion and reflection in strategic management. Strategic Management Journal, 32: $1500-1516$.

Hodgkinson, G. P., \& Healey, M. P. (2014). Coming in from the cold: The psychological foundations of radical innovation revisited. Industrial Marketing Management, 43: 13061313.

Hodgkinson, G. P., \& Johnson, G. (1994). Exploring the mental models of competitive strategists: The case for a processual approach. Journal of Management Studies, 31: 525551.

Hodgkinson, G.P., Langan-Fox, J., \& Sadler-Smith, E. (2008). Intuition: a fundamental bridging construct in the behavioural sciences. British Journal of Psychology, 99: 1-27.

Hodgkinson, G. P., \& Maule, A. J. (2002). The individual in the strategy process: Insights from behavioural decision research and cognitive mapping. In A. S. Huff \& M. Jenkins (Eds.), Mapping Strategic Knowledge (pp. 196-219). London: Sage.

Hodgkinson, G. P., Maule, A. J., \& Bown, N. J. (2004). Causal cognitive mapping in the organizational strategy field: A comparison of alternative elicitation procedures. Organizational Research Methods, 7(1), 3-26.

Hodgkinson, G. P., Maule, A. J., Bown, N. J., Pearman, A. D., \& Glaister, K. W. (2002). Further reflections on the elimination of framing bias in strategic decision making. Strategic Management Journal, 23(11), 1069-1076.

Hodgkinson, G. P., Sadler-Smith, E., Burke, L. A., Claxton, G., \& Sparrow, P. R. 2009. Intuition in organizations: Implications for strategic management. Long Range Planning, 42: 277297. 
Hodgkinson, G. P., \& Sparrow, P. R. (2002). The competent organization: A psychological analysis of the strategic management process. Open University Press.

Hodgkinson, G. P., \& Wright G. (2002). Confronting strategic inertia in a top management team: Learning from failure. Organization Studies, 23: 949-977.

Hodgkinson, G. P., Wright, R. P. \& Anderson, J. (2015). Emotionalizing strategy research with the repertory grid technique: Modifications and extensions to a robust procedure for mapping strategic knowledge. In G. Giovanni and W. Ocasio (Eds.), Advances in Strategic Management - Volume 32: Cognition and Strategy (pp. 505-547). Bingley, UK: Emerald.

Huff, A. S. (1978). Consensual uncertainty. Academy of Management Review, 3, 651-655.

Huff, A. S. (Ed.) (1990). Mapping strategic thought. Chichester: Wiley.

Huff, A. S. (2016). Project Innovation: Evidence-Informed, Open, Effectual, and Subjective. Project Management Journal, 47(2), 8-25.

Huff, A. S., \& Reger, R. K. (1987). A review of strategic process research. Journal of Management, 13(2), 211-236.

Huy Q. N. (2011). How middle managers' group-focus emotions and social identities influence strategy implementation. Strategic Management Journal , 32: 1387-1410.

Huy, Q. N. (2012). Emotions in strategic organization: Opportunities for impactful research. Strategic Organization 10: 240-247.

Isabella, L. A. (1990). Evolving interpretations as a change unfolds: How managers construe key organizational events. Academy of Management journal, 33(1), 7-41.

Jensen, M. C. \& Meckling, W. H. (1976). Theory of the Firm: Managerial Behavior, Agency Costs and Ownership Structure. Journal of Financial Economics, 3, 305-360.

Kahneman, D. (2011). Thinking Fast and Slow. London: Allen Lane.

Kahneman D., \& Klein G. (2009). Conditions for intuitive expertise: a failure to disagree. American Psychologist, 64(6): 515-526.

Kahneman D., \& Klein G. (2010). When can you trust your gut? McKinsey Quarterly. March: 58-67.

Kahneman, D., \& Tversky, A. (1984). Choices, values, and frames. American Psychologist, 39: 341-350. 
Karlsson N., Loewenstein, G., \& Seppi D. (2009). The ostrich effect: Selective attention to information. Journal of Risk and Uncertainty, 38: 95-115.

Lacey, L. and Galavan, R. J. (2015) Finding Value in Leaders' Decisions: an Empirical Examination of Leaders' Personal Values as antecedents of Strategic Choices. Personal Values and leadership Challenges Symposium. British Academy of Management Conference.

Lant, T. K., \& Shapira, Z. (Eds.) (2001). Organizational Cognition: Computation and Interpretation. Mahwah, NJ: Erlbaum.

Latham, G. P., Stajkovic, A. D., \& Locke, E. A. (2010 . The relevance and viability of subconscious goals in the workplace. Journal of Management, 36(1): 234-255.

Lieberman, M. D. (2007). Social cognitive neuroscience: A review of core processes. Annual Review of Psychology, 58: 259-289.

Lindblom, C. E. (1959). The science of "muddling through". Public Administration Review, 19, 79-88.

Lipshitz, R., Klein, G., Orasanu, J., \& Salas, E. (2001). Focus article: Taking stock of naturalistic decision making. Journal of Behavioral Decision Making, 14: 331-352.

Lipshitz, R. \& Strauss, O. (1997). Coping with Uncertainty: A Naturalistic Decision Making Analysis. Organizational Behavior and Human Decision Processes, 69: 149-163.

Liu, F., \& Maitlis, S. (2014). Emotional dynamics and strategizing processes: A study of strategic conversations in top team meetings. Journal of Management Studies, 51: 202234.

Loewenstein G. (2006). The pleasures and pains of information. Science 312: 704-706.

Loewenstein G, Rick S and Cohen JD. (2008). Neuroeconomics. Annual Review of Psychology 59: 647-672.

Louis MR \& Sutton RI. (1991). Switching cognitive gears: from habits of mind to active thinking. Human Relations, 44(1): 55-76.

Lykke, A. F. (1997). Defining Military Strategy. Military Review, 77, 182.

Meyer, A. (1982). Adapting to environmental jolts. Administrative Science Quarterly, 515-537.

Milliken, F. J. (1987). Three types of perceived uncertainty about the environment: State, effect, and response uncertainty. Academy of Management Review, 12, 133-143. 
Milliken, F. J. (1990). Perceiving and interpreting environmental change: An examination of college administrators' interpretation of changing demographics. Academy of management Journal, 33(1), 42-63.

Milliken. F. J. \& Lam, N. (2009). Making the decision to speak up or not: Implications for Organizational Learning. In J. Greenberg, M. Edwards, and C. Brinsfeld, (Eds.), Voice and Silence in Organizations, Sage.

Newell, A., \& Simon, H. A. (1976). Computer science as empirical inquiry: Symbols and search. Communications of the ACM, 19(3), 113-126.

Nonaka, I. (1994). A Dynamic Theory of Organizational Knowledge. Organization Science 5(1):14-37.

Pandza, K. and Thorpe, R. (2009), Creative Search and Strategic Sensemaking: Missing Dimensions in the Concept of Dynamic Capabilities. British Journal of Management, 20: S118-S131

Powell T.C. (2011). Neurostrategy. Strategic Management Journal, 32: 1484-1499.

Powell, T. C., \& Puccinelli, N. M. (2012). The brain as substitute for strategic organization. Strategic Organization, 10: 207-214.

Reger, R. K., \& Palmer, T. B. (1996). Managerial categorization of competitors: Using old maps to navigate new environments. Organization Science, 7: 22-39.

Rigby, D. \& Bilodeau, B. (2015). Management Tools \& Trends. Bain \& company.

Salas, E., Rosen, M. A., \& DiazGranados, D. (2010). Expertise-based intuition and decision making in organizations. Journal of Management, 36(4): 941-973.

Simon, H. A. (1979). Rational decision making in business organizations. The American economic review, 493-513.

Sund, K. J. (2013). Scanning, perceived uncertainty, and the interpretation of trends: A study of hotel directors' interpretation of demographic change. International Journal of Hospitality Management, 33(2): 294-303

Sund, K. J. (2015). Revisiting organizational interpretation and three types of uncertainty. International Journal of Organizational Analysis, 23(4): 588-605.

Sund, K. J. (2016). A Test of Perceptual Accuracy and Overconfidence in a Strategic Issue Context. In Uncertainty and Strategic Decision Making. Emerald Group Publishing Limited. 
Sund, K. J., Villarroel, J. A., \& Bogers, M. (2014). Organizational Aspects of Business Model Innovation: The Case of the European Postal Industry. Academy of Management Proceedings.

Sutcliffe, K. M., \& Weick K. E. (2008). Information overload revisited. In G. P. Hodgkinson, \& W. H. Starbuck (Eds.), The Oxford Handbook of Organizational Decision Making (pp. 56-75). Oxford, UK: Oxford University Press.

Teece, D. J (2007). Explicating dynamic capabilities: the nature and microfoundations of (sustainable) enterprise performance. Strategic Management Journal 28: 1319-1350.

Thomas, J. B., Clark, S. M., \& Gioia, D. A. (1993). Strategic sensemaking and organizational performance: Linkages among scanning, interpretation, action, and outcomes. Academy of Management journal, 36(2), 239-270.

Tversky A \& Kahneman D. (1981). The framing of decisions and the psychology of choice. Science 211: 453-458.

Venkataraman, S., Sarasvathy, S. D., Dew, N., \& Forster, W. R. (2012). Reflections on the 2010 AMR decade award: Whither the promise? Moving forward with entrepreneurship as a science of the artificial. Academy of Management Review, 37(1), 21-33.

Verganti, R. (2013). Design driven innovation: changing the rules of competition by radically innovating what things mean. Harvard Business Press.

Vuori, N., \& Vuori, T. (2014). Comment on "Heuristics in the strategy context" by Bingham and Eisenhardt (2011). Strategic Management Journal, 35: 1689-1697.

Walsh, J. P. (1995). Managerial and organizational cognition: Notes from a trip down memory lane. Organization Science, 6: 280-321.

Weick, K. E. (1995). Sensemaking in organizations (Vol. 3). Sage.

Weick, K., Sutcliffe, K. and Obstfeld, D. (2005). Organizing and the process of sense-making. Organization Science, 16:409-421.

Wright, R. P. (2004). Top managers'strategic cognitions of the strategy making process:

Differences between high and low performing firms. Journal of General Management, 30(1): 61-78.

Wright, R. P. (2008). Eliciting cognitions of strategizing using advanced repertory grids in a world constructed and reconstructed. Organizational Research Methods, 11: 753-769. 